\title{
Historiografia literária brasileira hoje: hibridismo e multiplicidade
}

\section{Brazilian literary historiography today: hybridism and multiplicity}

\author{
Helena Bonito Couto Pereira* \\ Universidade Presbiteriana Mackenzie \\ helenabonito.pereira@gmail.com
}

\begin{abstract}
RESUMO: A história da literatura brasileira registrada em compêndios e obras de referência apresenta, em sucessivos movimentos, os escritores, as obras e suas circunstâncias, desde o período colonial até o final do século passado. A partir deste último período, todavia, nota-se nessas obras uma certa incompletude, decorrente, entre outras razões, do tempo necessário aos procedimentos de seleção, análise e interpretação de dados sobre a variada e volumosa produção literária. Decorridos já dois decênios do século XXI, propõe-se neste artigo a retomada e a complementação das tendências da produção recente, tais como o hibridismo, a multiplicidade e a heterogeneidade, em suas relações de continuidade ou ruptura com a produção do século passado. Espera-se reunir neste texto subsídios para complementar a construção da historiografia literária brasileira.
\end{abstract}

PALAVRAS-CHAVE: Historiografia literária. Literatura contemporânea. Literatura brasileira.

ABSTRACT: The history of Brazilian literature recorded in compendia and reference works presents, in successive movements, the writers, the works and their circumstances, from the colonial period until the end of the last century. From this last period on, however, a certain incompleteness can be observed in these works, resulting, among other reasons, from the time necessary for the procedures of selection, analysis and interpretation of data on the varied and voluminous literary production. After two decades of the $21^{\text {st }}$ century, this article proposes the resumption and completion of recent production trends, such as hybridism and multiplicity, in their relations of continuity or rupture with the last century's production. It is hoped to gather in this text subsidies to complement the construction of Brazilian literary historiography. KEYWORDS: Literary historiography. Contemporary literature. Brazilian literature.

\section{Considerações iniciais}

O maior desafio para a historiografia da literatura brasileira no século XXI reside na tentativa de se definir ou categorizar os fenômenos artístico-culturais - como o

\footnotetext{
* Doutora e Mestra em Letras (Língua e Literatura Francesa) pela Universidade de São Paulo, com Estágio Pós-doutoral na Universidade da Califórnia em Riverside (2006). Professora titular e docente permanente no Programa de Pós-Graduação em Letras da Universidade Presbiteriana Mackenzie.
} 
literário - que, ainda em movimento, fluem nas inquietas ondas da contemporaneidade. Como observou Schöllhammer (2011), a contemporaneidade só pode ser representada se o escritor for capaz de se orientar no escuro, mesmo que reconheça a quase impossibilidade de apreensão do momento presente, essa "realidade de difícil captura". Tal observação aplica-se a todos os teóricos, críticos e historiadores de literatura com olhos voltados para as duas décadas deste século, que ora se completam.

A proposta deste artigo é elencar componentes para empreender a discussão sobre a escrita de uma possível historiografia literária que dê conta desse período para construir, ainda que, inegavelmente, de modo parcial e incompleto, uma historiografia literária representativa da contemporaneidade. A pesquisa de dados inicia-se, obrigatoriamente, nos registros histórico-literários publicados e reconhecidos em sua condição de documentos referenciais para os pesquisadores desse campo. Dada a amplitude do tema, estas reflexões limitam-se ao estudo do romance, aqui considerado como gênero em que se explicita com nitidez a intensa relação entre a arte literária e seu contexto.

\section{Antecedentes historiográficos}

Em Historiografia da literatura brasileira. Textos fundadores (2014), Roberto Acízelo apresenta textos que contribuíram, cada qual a seu modo, para a construção historiográfica. Dentre esses é possível destacar, por exemplo, o "Instinto de nacionalidade: notícia da atual literatura brasileira (1873)", em que Machado de Assis propõe que cada escritor se identifique como homem de seu tempo e de seu país, mesmo que trate de "assuntos remotos no tempo e no espaço". (ASSIS, 1873). Outro precursor da historiografia literária foi Francisco Sotero dos Reis, cujo texto "Periodização da literatura brasileira: plano para um curso (1867)" consta da seleção de Acízelo, ao lado de textos de outros intelectuais da época, em especial os que seriam consagrados como a tríade fundadora da historiografia e da crítica entre nós: Araripe Júnior, José Veríssimo e Sílvio Romero¹.

\footnotetext{
${ }^{1}$ Textos consignados sobre esses três crtíticos por Acízelo como antecedentes historiográficos: "Carta sobre a literatura brasílica" e "Ponto de vista para o estudo da literatura brasileira", de Tristão de Alencar Araripe Júnior; "A literatura brasileira: sua formação e destino" e "O estado atual da literatura brasileira e a questão da propriedade literária", de José Veríssimo Dias de Matos; "A literatura brasileira e a crítica moderna" e "O nacionalismo literário", de Sílvio Vasconcelos da Silveira Romero.
} 
Romero escreveu a mais completa história da literatura brasileira do século XIX, em cinco volumes. Apontou a existência de literatura no Brasil, o que havia sido alvo de controvérsias na época, por se tratar de afirmar a existência de uma nova literatura, que se expressava em língua já possuidora de literatura própria: "Há literatura - o prova a crítica e a história [...] sempre que num povo encontra-se a consciência de si mesmo" (ACíZELO, 2014, p. 445). Todavia, em meio aos esforços para compor sua obra historiográfica, ele não conseguiu delimitar o campo, inserindo filosofia, folclore, sociologia etc., em uma visão fortemente distorcida pelo compromisso ideológico com o cientificismo (positivista e racista) próprio de seu tempo.

Apenas na segunda metade do século $X X$ surgiram historiografias mais consistentes ou mais completas. São estudos que estabelecem a periodização e destacam percursos (e percalços) de escritores e obras em diferentes momentos. Em 1957, ao publicar Formação da literatura brasileira: momentos decisivos, Antonio Candido inaugurou uma tendência historiográfica com foco não apenas nos fenômenos literários, como também nas circunstâncias socioeconômicas que constituíam o solo para que esses fenômenos vicejassem. Estabelecendo, já no subtítulo, sua ênfase no período de formação, o pesquisador e crítico reportou sua historiografia literária até a consolidação do romantismo, quando se concluiu a fase formativa da literatura brasileira. Do ponto de vista deste estudo, vale destacar uma contribuição do renomado historiador e crítico ao estudo dos antecedentes da historiografia contemporânea, no ensaio "A nova narrativa" (CANDIDO, 1989).

Nos anos cinquenta, publicou-se outra obra historiográfica de fôlego, $A$ literatura no Brasil, em seis volumes, coordenada por Afrânio Coutinho, publicação que mobilizou um verdadeiro contingente de críticos e historiadores literários do mais alto nível - como Eugênio Gomes, Luiz Costa Lima, Wilson Martins, Soares Amora, dentre outros. A primeira edição contemplou, evidentemente, a produção literária divulgada até meados do século, e, dado o caráter coletivo dessa realização, houve uma única atualização em tempos recentes.

A publicação da História concisa da literatura brasileira por Alfredo Bosi, em 1970, significou o surgimento de uma obra de referência que supriu uma lacuna na área, pois alcançou sucessivas reedições, a mais recente delas em 2017. Posteriormente, o autor acrescentou um capítulo final, sobre "tendências contemporâneas", abarcando parte da produção mais recente. 
Não tão conhecida, mas ainda resistente no catálogo das editoras, é a História da literatura brasileira, em 4 volumes, publicada por Massaud Moisés entre 1983 e 1987, que alcançou nova edição em 2019. No quarto volume (atualizado como terceiro volume, na edição mais recente), no capítulo "Modernismo", encontra-se o subcapítulo “Tendências contemporâneas" que, por sua vez, traz outro subtítulo, "Atualidade”, com referências a escritores e obras dos anos 80, como João Gilberto Noll, João Ubaldo Ribeiro, Pedro Nava, Ignacio de Loyola Brandão e outros.

Nos anos 90, duas novas obras de referência vieram somar-se a esse conjunto. Na primeira delas, a História da literatura brasileira da pesquisadora e crítica italiana Luciana Stegagno Picchio, publicada em 1997 e reeditada em 2004, destaca-se o interesse em recobrir as manifestações literárias até o tempo de sua escrita. Essa historiadora mostrou seu pioneirismo, ao inserir no $16^{\circ}$ capítulo, "Dos anos do golpe ao fim do século", um subtítulo específico: "A escrita das mulheres". Visando contemplar, ainda que de modo bastante sumário, as produções literárias vindas a público praticamente até a data da publicação de sua história literária, Picchio mencionou, entre outros, autores praticamente estreantes na época e que alcançariam boa repercussão posteriormente, como Bernardo Carvalho, Patrícia Melo, Cristovão Tezza.

A História da Literatura brasileira de José Aderaldo Castelo, lançada em 1999 em dois volumes, permaneceu apartada de seu próprio tempo de publicação. Nessa obra, apêndices aos capítulos finais apresentam listas com autores "estreantes em 40 e 50" e "estreantes em 60 e 70". (CASTELLO, 1999, p. 483-485).

Produção relativamente recente é a História da literatura brasileira. Da Carta de Caminha aos contemporâneos, publicada por Carlos Nejar em 2011, com apoio da Fundação Biblioteca Nacional. A despeito da data de publicação, a obra de Nejar não contém dados historiográficos mais recentes: no último capítulo voltado para a prosa de ficção, "Década de 1960. Ficção", encontra-se o subtítulo "Alguns grandes nomes na ficção surgidos após a década de 1970". Como autores com romances publicados a partir de 2000, a obra limita-se a apontar, salvo engano, apenas Luiz Antônio de Assis Brasil, Ana Maria Machado e Silviano Santiago.

A despeito de sua importância em nossa historiografia literária, essas obras, em razão de diversos fatores, em especial o período de sua produção, parecem oferecer escassas contribuições para a configuração da nossa historiografia literária, a partir da década de 1980. 


\section{Meio século de história literária}

Cinco decênios correspondem a um longo período, marcado por transformações socioeconômicas, artísticas e culturais que repercutem nas narrativas literárias em dois aspectos - interno e externo -, que se mostram, paradoxalmente, opostos e indissociáveis. Considerando aspectos externos, pode mudar todo o contexto de produção, divulgação e comercialização da produção literária, em meio às circunstâncias econômicas ou políticas, tais como o ingresso na cultura de massa, a invasão das mídias e, mais recentemente, a globalização. Aspectos interiores compreendem a incorporação desses mesmos fatores ao âmago do discurso literário propriamente dito, fenômeno hoje compreendido como hibridização, ao lado de outras inovações em gêneros, vozes, modalidades. Tais inovações não impedem que componentes da escrita tradicional se mantenham, com ou sem alterações.

O estabelecimento de balizas temporais para a produção literária, imprescindível à construção do discurso historiográfico, vê-se às voltas com duas questões que merecem ser examinadas à luz das ponderações de Tania Pellegrini. A primeira delas trata da dificuldade para a construção de consensos sobre as características dominantes em um período porque estão inevitavelmente acompanhadas por outras, residuais ou emergentes. Consequentemente, a delimitação de balizas temporais - caso não seja realizada de modo adequado incorre no risco de apagar antecedentes significativos. Além disso, a produção literária processa-se em movimentos contínuos, em uma acumulação lenta, tensa, sujeita a contradições. Em vista disso, afirma a pesquisadora:

Considerando-se mais uma vez que o desenvolvimento das formas artísticas se dá em processo e que, nele, o binômio continuidade / ruptura é determinante, pois uma não existe sem a outra, acredito que o qualificativo mais adequado [...] seja transitório. [...] Aqui, transitório refere-se ao conjunto da prosa do momento, de fato plural, fértil e híbrido, que aparenta romper várias matrizes estabelecidas, transitando pela história. (PELLEGRINI, 2018, p. 222)

Esse reconhecimento de um componente transitório na apreciação da literatura contemporânea, embora aparentemente contraditório em relação ao intuito de identificar características das obras em diferentes períodos e em relação a tendências ou vertentes, na verdade é um contraponto indispensável a uma reavaliação histórico- 
crítica, a realizar-se posteriormente. A impressão de transitoriedade perpassa todos os procedimentos de análise e intepretação aqui empregados para o embasamento da periodização exposta a seguir.

Feitas essas ponderações, é preciso ir adiante, pois a historiografia, como componente do campo metaliterário, ao lado da crítica e da teoria, não pode prescindir de interpretações, devidamente sistematizadas, sobre a produção literária e seu contexto. Voltando ao propósito deste texto, exposto nos parágrafos iniciais, o alvo destas reflexões é colocar em destaque o que se produziu e o que marcou mais intensamente leitores e críticos nos decênios posteriores a 1980. Levando em conta, na esteira de Pellegrini, o caráter transitório de qualquer periodização, é necessário ressaltar a relevância do binômio continuidade / ruptura, tendo por alvo, adiante, o estabelecimento de algumas constantes que persistem em meio às variantes.

Observada a relativa incompletude documental nos compêndios historiográficos, a continuidade da construção da nossa história literária depende de uma complementação baseada em textos de pesquisadores e críticos dedicados a esta temática, ressaltando a relevância de textos de historiadores sobre esse período. Além do já mencionado ensaio de Candido, "A nova narrativa" (1989), Alfredo Bosi organizou uma coletânea de contos em cujo prefácio, "Situação e formas do conto brasileiro contemporâneo" delineou as tendências que se mostrariam persistentes nos decênios seguintes. Identificou as "linhas de força" que atravessariam a produção romanesca até o fim do milênio e que, resumidas aos movimentos principais, compreendem: realismo documental, crítico e o que classificou como "brutalista"; intimismo memorialista, visionário ou fantástico; experimentalismo no nível da linguagem; regionalismo. (1975, p. 9-10).

A complementação revela-se uma tarefa particularmente desafiadora, diante da quantidade de textos críticos que se multiplicam continuamente, em especial nos periódicos científicos. Assumindo um critério de qualidade, sem perder de vista o risco - altamente previsível - de omissões, a continuidade deste estudo fundamenta-se em obras de pesquisadores como Beatriz Resende, Karl-Eric Schöllhammer, Regina Dalcastagnè, Tania Pellegrini e Flávio Carneiro, dentre outros, cujos textos são consultados em sua condição de "recortes", ou visadas parciais, que trazem interpretações significativas sobre as obras publicadas no período.

A construção da historiografia literária recente é uma caminhada sujeita aos tropeços decorrentes da impossibilidade de captura do que nos cerca e da dificuldade 
na tentativa de sistematizar conjuntos diversificados, híbridos, múltiplos. Vale ressaltar, finalmente, que se reconhece neste texto a incontornável parcialidade da seleção e interpretação de dados e que se repele qualquer intenção totalizante ou formadora de cânones. Dessa forma, a sistematização (sem a qual não há historiografia) pode ser estabelecida a partir da divisão desses decênios em três períodos: contexto ditatorial; escrita finissecular e primórdios do século XXI.

\subsection{Período ditatorial ${ }^{2}$}

Historicamente, situa-se na "década de 70" o auge do chamado Milagre Brasileiro, período de euforia de uma classe média que finalmente alcançava bens de consumo e caminhava para a massificação, sentimentos que camuflavam as vozes contrárias ao governo militar. No longo período entre 1964 com o golpe militar, e 1985, com a derrocada da ditadura, ocorreram pelo menos duas crises que desembocaram em movimentos sucessivos: o primeiro, em que se intensificou a repressão, e um segundo que, impulsionado pelas movimentações da sociedade civil, instaurou a distensão e, por fim, a abertura. Processaram-se mudanças que só podem ser compreendidas em conjunto: "modernização, desenvolvimento capitalista, autoritarismo e lutas sociais pela constituição de uma esfera pública" como observou Ridenti (2014, p. 44).

Nos anos iniciais, referidos por Gaspari (2002) como “ditadura envergonhada”, a censura ostensiva institucionalizou-se como mecanismo auxiliar da repressão, tomando como alvos preferenciais a imprensa periódica, a tevê, o teatro e o cinema. A literatura, consumida por um público especializado e em número bem reduzido no conjunto da classe média, não sofreu a vigilância implacável que se abateu contra outros setores da produção cultural, tendo sido ocasionais as apreensões ou condenações de obras literárias, dentre elas Feliz ano novo, de Rubem Fonseca, Zero, de Ignácio de Loyola Brandão, Em câmara lenta, de Renato Tapajós.

Muitos escritores sentiram-se ameaçados pelo espectro da censura e, como observou Flora Süssekind: "Esse é o período em que mais claramente se passa a

\footnotetext{
2 Neste tópico sobre o período ditatorial, são retomadas, em breve síntese, reflexões publicadas pela autora em livros ou artigos, em diferentes datas.
} 
sentir a presença de um censor ao lado da máquina de escrever. Uma espécie de Fleury das letras acompanha de perto a produção literária dos anos 70”. (2004, p. 31)

Uma das saídas para superar os constrangimentos impostos pela ditadura foi a adesão à escrita alegórica que, na expressão de Renato Franco, "parece ter sido um dos conceitos-chave empregados pela crítica mais empenhada em interpretar o romance da década de 70". (1998, 144)

A interpretação dos modos de narrar desse período suscitou controvérsias entre os críticos: de um lado, Süssekind fez uma cobrança extemporânea, considerando que as alegorias impediam a pluralidade e aniquilavam a polissemia do texto literário, o que a levou a propugnar por um encaminhamento "menos documental ou menos alegórico" (2004, p. 103). Em sentido oposto, Renato Franco recusou qualquer possibilidade de identificação entre alegoria e censura, apontando surgimento da alegoria como consequência "da morte do sujeito clássico, aliada ao processo irreversível de desintegração dos objetos" (1998, p. 148). Dessa forma, a representação alegórica ultrapassaria um impulso de fuga, circunstancial, em face da censura. A alegoria foi apenas um dos modos de representação, que devem ser compreendidos não só em sua multiplicidade, como na sua possível permanência ao longo dos períodos seguintes.

Contemplando explicitamente a narrativa desse período, posterior às publicações de Clarice Lispector e Guimarães Rosa, Candido apontou a existência, ao lado de uma linha experimental e renovadora, de duas modalidades de representação. A primeira se compõe de "manifestações fortes, na linha mais ou menos tradicional de fatura", próximas do realismo; a outra, de "inconformismo e oposição", definida por ele como "literatura do contra": contra a escrita elegante, a convenção realista, a lógica narrativa e até mesmo contra a ordem social. (1989, p. 209). Destacou, adiante, como seus temas "guerrilha, criminalidade solta, superpopulação, migração para as cidades, quebra do ritmo estabelecido de vida, marginalidade econômica e social”. (CANDIDO, 1989, p. 212). A migração para as cidades teria um efeito direto e permanente, em nossas letras como em todo o país, o da apropriação da vida urbana pela literatura.

Além da breve menção a uma linha experimental, foram alvo de suas considerações os aspectos estéticos da ficção literária:

Convém lembrar que a ruptura das normas pode ocorrer por meio do 
recurso a sinais gráficos, figuras, fotografias, não apenas inseridos em seu texto, mas fazendo parte orgânica do projeto gráfico dos livros [...]. Muitos autores mantêm uma linha que se poderia chamar de mais tradicional, sem dizer com isso que seja convencional, pois na verdade operam dentro dela com audácia, na procura de uma naturalidade coloquial buscada desde o Modernismo dos anos 20, e que só agora parece instalar-se de fato na prática geral da literatura. $(1999$, p. 211)

Candido apontou, talvez de modo pioneiro, aspectos que se tornariam extremamente frequentes em nossa literatura, indicando como traço característico "a ficcionalização de outros gêneros (crônica, autobiografia), sem falar da vocação ficcional transferida para fora da palavra escrita, indo levar a diversas artes o que era substância do conto e do romance: cinema, teatro, telenovela" (1989, p. 210)

O modo de representação realista constituiu, sem dúvida, a linha de força predominante no período, como apontou Davi Arrigucci Júnior, em "Jornal, realismo, alegoria: o romance brasileiro recente". Ocorreu então "um desejo muito forte de voltar à literatura mimética, de fazer uma literatura próxima do realismo [...] e com um lastro muito forte de documento" (1999, p. 77). O impulso realista se sustenta, empregando técnicas próximas do relato jornalístico, embora as condições sociais favoreçam a escrita alegórica. (1999, p. 91) Jornalismo e literatura andaram próximos no período, pois um fato ou notícia censurado podia eventualmente transformar-se em obra literária. Assim vicejou outra vertente de textos realistas, marcados pela pobreza na elaboração textual, publicados no formato conhecido como romance jornalístico ou romance-reportagem. Sem grande variedade temática, relacionados muitas vezes ao noticiário policial, tais romances têm em comum o descompromisso com a elaboração estética, aspecto mal trabalhado que dificilmente os distingue de textos jornalísticos ou documentais.

\subsection{A escrita finissecular: anos 80 e 90}

O ingresso definitivo da sociedade brasileira no mundo do consumo e as contínuas inovações aportadas pela tecnologia às mídias eletrônicas e audiovisuais contribuíram para alterações significativas na produção literária e em sua veiculação, o que se acentuaria nos períodos seguintes, com a globalização. Recursos usuais em períodos precedentes, como o fragmentarismo, a variedade de vozes narrativas, a pluralidade de estilos e a interação com a indústria cultural e com as mídias 
audiovisuais, incorporaram-se à narrativa ficcional.

Em estudo que recobre os três decênios finais do século passado, Therezinha Barbieri (2003) discute as relações da literatura com a cultura de massa, atribuindoIhe o qualificativo de impura. Essa impureza seria uma condição adquirida pela literatura em razão de sua permeabilidade a diferentes discursos, ao diálogo instaurado entre a letra e a imagem ("a palavra literária em diálogo com signos icônicos") e a franca exposição às vicissitudes do mercado (2003, p. 24-26). No bojo dessa adesão às mídias, teria ocorrido também, por parte de escritores, o empenho para

[...] resgatar da massa indiferenciada do público mais e mais leitores ativos e prontos a partilhar o jogo literário. Em lugar de um leitor fechado em seu pequeno mundo, como o garoto Marcel de Em busca do tempo perdido, os ficcionistas atuais [dos anos 80 e 90] se empenham em atrair leitores expostos ao bombardeio dos meios de comunicação de massa. O discurso narrativo não mais oculta o diálogo que dentro dele se instala com as formas de expressão próprias desses meios e a linguagem literária em fase de mutação. Ao ler qualquer uma dessas narrativas mais recentes, tem-se a impressão de assistir a atores que representam, em vez de acompanhar personagens em processo de autodesvelamento específico da narrativa literária. (BARBIERI, 2003, p. 33)

O diálogo entre a letra e a imagem corresponde ao reconhecimento de uma interação que se intensificou continuamente e permanece até hoje. É importante registrar que esse fenômeno não era inédito, pois já se verificava na prosa desde os anos 60 e 70, como em Lúcia MacCartney, de Rubem Fonseca, ou Zero, de Ignacio de Loyola Brandão. As narrativas dos anos seguintes incorporaram decididamente os meios de comunicação de massa e o mundo do consumo, mencionando-os com frequência e tornando-os componentes da construção textual. Referências às produções artísticas veiculadas nas mídias encontram-se em profusão, evidenciando a estreita conexão entre o mundo representado e a realidade concreta em que o texto ficcional se inspira.

Do diálogo da narrativa literária com as mídias derivaram, direta ou indiretamente, outros recursos narrativos. Um deles, existente em período anterior, mas ora intensificado, foi o fragmentarismo, ou desintegração formal, que se transformou em princípio artístico. Como assinalou Otsuka,

A montagem na literatura (assim como a colagem na pintura), ao contrário do que ocorre no cinema, é um princípio artístico que 
pressupõe a fragmentação da realidade, e quase sempre associa-se à concepção de que as partes manifestamente heterogêneas que compõem a obra são irreconciliáveis. [...] o procedimento expõe a obra como artifício, desfazendo a ilusão ficcional. (2001, p. 30)

A fragmentação como fator estético e temático impregna com força uma vertente que pode ser considerada pós-moderna, ainda que o pós-modernismo nunca tenha alcançado manifestações entusiásticas por parte da crítica finissecular, que o contemplou com raros estudos. Merece destaque, nesse sentido, "O narrador pósmoderno", texto em que Silviano Santiago discute o narrador inserido na sociedade midiática que é capaz, ao mesmo tempo, de torná-la alvo de suas investidas críticas (2002, p. 60).

Ao fragmentarismo que se expõe claramente na camada formal corresponde um procedimento associado aos componentes estéticos e temáticos das narrativas. Alinhadas com a fragmentação e com outros recursos que podem ser considerados pós-modernos, registra-se a intensificação de transgressões gráficas e morfossintáticas na camada significante, ou a representação caótica de personagens à deriva, em espaços degradados, no âmbito temático. Essas personagens problemáticas estão em permanente dissonância com o mundo, circulando em espaços labirínticos ou indefinidos. Múltiplos planos temporais se interpenetram, sem coerência, contribuindo também para a instauração do caos. Os contornos dos seres e das coisas, com frequência, adquirem dimensões irreais, pois a tentativa de representar os destinos humanos leva o romancista a adentrar o reino do absurdo ou, mais raramente, do fantástico, para encarar a falta de sentido da vida contemporânea.

Romances que incorporaram traços semelhantes a esses, como, por exemplo, Rastros do verão ou A fúria do corpo, de João Gilberto Noll, ou ainda Estorvo, de Chico Buarque, podem ser considerados pós-modernos, embora não tenha ecoado, na crítica brasileira, a definição de Linda Hutcheon, que o considera: "um fenômeno cultural definível, digno de ter uma poética articulada" (1991, p. 61).

A força do mercado empurrou produtos da indústria cultural e da tecnologia para o interior da ficção literária, suscitando mutações, inclusive nos gêneros narrativos, como observou Tânia Pellegrini (1999), apontando novos matizes, um tanto contraditórios. Ao analisar novos matizes presentes no gênero policial, que adquiriu enorme relevância na prosa de Rubem Fonseca, afirma a pesquisadora que nesse gênero tornou-se possível 
[...] formalizar elementos da mais destacada modernidade estilística, tais como a metalinguagem, a combinação de discurso direto e monólogo interior, que subvertem a cronologia e conseguem especializar o tempo, além de um meticuloso trabalho de fotografia, pela acumulação de tomadas minuciosas, que incorporam mais uma vez o horizonte técnico do cinema e, até certo ponto, evitam o esquematismo dos best sellers. (PELLEGRINI, 1999, p. 79)

Ganharam novos matizes também as modalidades de narrativa realista. Ao lado do realismo documental de fundo ideológico, contra a opressão da ditadura militar, que esteve em voga em períodos anteriores, e do realismo crítico marcante da prosa dos anos 30 e 40 do século passado, já havia sido reconhecido nos anos 70 o realismo brutalista, que, em contundentes representações da violência, denunciava a precariedade das condições de vida nos centros urbanos, incorporando inclusive o ponto de vista, o léxico e o coloquialismo das classes marginalizadas. Presente nos contos e romances de Rubem Fonseca, o realismo brutalista permaneceu ao longo do tempo, visto que esse escritor se tornou referência para vários escritores, declaradamente inspirados em sua prosa. Hiper-realismo e realismo crítico estão bastante próximo dessa modalidade, expressando-se em diferentes graus de intensidade.

As modalidades narrativas finisseculares estão bem representadas em duas coletâneas de contos organizadas por Nelson de Oliveira, Geração 90: manuscritos de computador, publicada em 2001 e Geração 90: Os transgressores, lançada dois anos depois.

Os autores dos contos, jovens sintonizados com a mídia digital e outras mídias, dispunham-se a elaborar narrativas experimentais, em contraposição à escrita formalmente tradicional, mas, por diferentes razões, nem todos se alinharam à proposta. O almejado experimentalismo colocou-se em oposição à escrita tradicional que trazia à nossa literatura obras magistrais, como, por exemplo, o Relato de um certo Oriente, de Milton Hatoum. Instaurou-se então uma polêmica entre tradição e experimentalismo, que teve o mérito de atrair as atenções para a ficção brasileira do último decênio do século, porém essa polarização mostrou-se desnecessária, pois diferentes modalidades de ficção podem e devem coexistir no mesmo espaço, cada qual em busca de seus leitores. $O$ formalismo inovador, radical no arranjo vocabular e também na expressão gráfica, por um lado, e a escrita tradicional, densa, carregada de linguagem metafórica e subjetividade, por outro, são extremos de um oceano com águas que se interpenetram ou se fundem, capazes de multiplicar infinitamente os matizes da produção literária. Corrobora essa 
afirmação o fato de haver, nesses dois volumes", vários contos sem propostas esteticamente inovadoras, o que não interfere em sua qualidade literária.

Em paralelo a inovações experimentais, narrativas de fatura relativamente tradicional foram publicadas no período, sob variados enfoques, como o intimista, ou memorialista, de um lado, e o regionalista, de outro. As temáticas permanecem, porém o modo de narrar modifica-se, predominantemente sem rupturas formais. Na literatura intimista ou memorialista, enredos, espaços e exterioridades ficam em segundo plano, havendo prioridade para questões de natureza interna em relação a personagens e/ou narradores, ou seja, para a interioridade, o mundo psíquico das personagens. A memória é muitas vezes a força-motriz desses enredos, em que um narrador em primeira pessoa pode ou não derivar para a escrita autobiográfica, com ênfase ao que Otsuka define como "subjetividade esfacelada" (2011, p. 205). Solidão e incomunicabilidade permanecem como temas inerentes à grande literatura. Começam a se tornar mais explícitas temáticas associadas a sexualidade, homoerotismo, feminismo, dentre outras possibilidades que se expandiram nos decênios seguintes.

\subsection{Nos primórdios do século XXI}

Nos anos iniciais do século XXI, a literatura brasileira viveu um período extraordinariamente positivo, com o despontar de novos escritores - e, finalmente, também de escritoras. Um dos fatores para que alcançassem visibilidade junto ao público e espaço no mercado editorial foi a multiplicação de eventos literários. As premiações tradicionais - Prêmio Jabuti, Prêmio Oceanos (em versões anteriores, Portugal-Telecom), Prêmio São Paulo - asseguraram retorno financeiro e condições para a continuidade da produção a muitos deles. A quantidade de eventos foi um fator decisivo para a visibilidade na mídia e para o contato direto entre escritores e leitores. Ao lado das pioneiras Jornadas literárias de Passo Fundo, realizadas desde os anos 80, e das tradicionais Bienais de São Paulo e do Rio de Janeiro, as feiras, festas e jornadas contribuíram para o incremento da leitura (sempre aquém do desejável) e, com apoio de operações de marketing, asseguraram a presença e a vitalidade do mercado editorial. O primeiro passo, nesse sentido, havia sido dado pela Festa Literária Internacional de Paraty (FLIP), realizada anualmente desde 2003, modelo adotado em dezenas de eventos mais modestos que se espalharam pelo Brasil afora. Nesse contexto, os jovens escritores passaram a encontrar espaços para difusão de suas obras, em palestras e outras atividades - às vezes verdadeiras performances - 
que envolvem diretamente o público, podendo consagrar-se sem depender exclusivamente das editoras, do mercado, e menos ainda das esferas acadêmicas.

A visibilidade para o romance brasileiro inaugurada nos primórdios do século XXI foi um dos fatores que propiciaram maior número de publicações, como observou Beatriz Resende:

A primeira evidência que salta aos olhos [...] é a fertilidade dessa forma de expressão entre nós, hoje. Apesar das queixas repetidas de que há poucos leitores, de que o livro vende pouco etc., é fácil constatar que se publica muito, que novos escritores e editoras surgem todos os dias, e que comenta-se e consome-se literatura. Nas grandes cidades, novas livrarias partilham o mesmo espaço com outras formas de lazer, tornando o convívio com o livro mais sedutor. Surgiram nos últimos anos novos prêmios literários com valores bem maiores que no passado (2008, p. 16)

O período de relativa prosperidade vivido pelo Brasil manteve-se por algum tempo, porém não se confirmou o otimismo de Resende sobre a abertura de livrarias em 2008. No início de 2020, o súbito surgimento do Coronavírus, ou Covid-19 deu origem a uma crise sanitária e humanitária, agravada pela impossibilidade de se avaliar a verdadeira dimensão da contração da economia brasileira e mundial. Ante a inexistência de tratamento eficaz, imunidade preexistente ou vacinas, preconizou-se o isolamento social que, como observa Grisotti (2020), trouxe como consequência "profundos impactos sociais, culturais e econômicos, assim como estratégias de resiliência frente às incertezas".

No que se refere ao mundo do livro e da leitura, a crise havia começado antes, como afirma a pesquisa coordenada pela Câmara Brasileira do Livro (CBL) e pelo Sindicato Nacional dos Editores de Livros (SNEL), "A série histórica registra um decréscimo de 20\% no faturamento total de 2006 a 2019". (CBL, 2020). O decréscimo continuou a acentuar-se após o início da pandemia, porém, sendo a produção literária apenas parte desse mercado, houve circunstâncias que a particularizaram. No artigo on line "Como o mercado de livros foi impactado pela pandemia?" Thais Monteiro (2020) observa que "se, por um lado, o início do período de isolamento social contribuiu para a diminuição das vendas, por outro, mais tempo em casa e a falta de outras atividades sociais pode ter contribuído para uma melhora no hábito de leitura". Além disso, "sem grande representatividade antes do confinamento, as vendas no digital tiveram ganhos. [...] A procura por e-books aumentou". 
No bojo dessa retomada da leitura literária e das inquietações associadas à pandemia, despontaram textos ficcionais, inclusive com concursos nas mídias eletrônicas, convidando autores a enviarem seus contos e crônicas relacionados ao momento vivido. E-books e livros impressos repercutem entre leitores e em resenhas críticas on line, como os romances Ana de Corona, de Gisele Mirabai, Corpos secos, de autoria coletiva (GEISLER, FERRONI, POLESSO, MACHADO, 2020) ou as coletâneas Histórias da pandemia (SEREZA; MONTELEONE, 2020) e Amores em quarentena (DAMASO, 2020).

Desse modo, a despeito do desenrolar da crise, a produção literária, conectada às mídias eletrônicas há algum tempo, e mais recentemente também às mídias e redes sociais, alcançou um processo de exposição e renovação sem precedentes, embora hoje seja impossível vislumbrar se haverá efetivas condições para sua sustentação. Mas o êxito não teria sido possível sem o surgimento de uma plêiade de escritores - e, finalmente, de escritoras - que expõem suas obras à leitura e à crítica nesses espaços midiáticos, complementos hoje indispensáveis à veiculação das obras impressas.

A fertilidade na produção literária referida por Resende expande-se em diferentes tendências ou vertentes. Algumas delas são remanescentes de períodos anteriores, como realismo, memorialismo, regionalismo ou escrita experimental, além da recentemente incorporada hibridização entre o texto literário e as linguagens midiáticas. Outras vertentes abrem-se para o ingresso de participantes social e economicamente desfavorecidos, oriundos das camadas periféricas, e para representantes das minorias étnicas e de gênero. Não só novas vozes, como novas temáticas conquistaram espaço: identidade e migração surgem com força nas narrativas contemporâneas.

Assim se compõe o panorama de fertilidade indicado por Resende, que comporta a multiplicidade, definida como "a heterogeneidade em convívio, não excludente", na linguagem, nos formatos, na relação com o leitor e no suporte, por meio da comunicação informatizada. O efeito da multiplicidade, segundo a mesma pesquisadora, é o espaço conquistado por novas vozes "que até recentemente estavam afastadas do universo literário" (2008, p. 17), vozes das periferias, usando seu próprio discurso, o que vem alterar um quadro persistente, em nossa literatura, na qual, inconsciente ou involuntariamente, têm sido praticadas as formas de exclusão. De acordo com Regina Dalcastagnè, 
Há uma tendência na literatura brasileira contemporânea em abordar os pobres se não de forma estereotipada, ao menos de um modo distante, recorrendo muitas vezes a uma "objetividade jornalística" que nos coloca diante de gestos e ação, mas não de pensamentos e reflexão, o que parece área reservada para as personagens de classe média e das elites). (2012, p. 139)

A multiplicidade contempla igualmente a literatura de autoria feminina, que tem dado largas passadas rumo à criação de um espaço próprio, como registrou Luiza Lobo em "A literatura de autoria feminina na América Latina". A escritora toma consciência de seu papel social e passa expressar-se "a partir de um ponto de vista e de um sujeito de representação próprios"3, constituindo um olhar de diferença. Verifica-se, um reconhecimento do valor dessa escrita, como demonstram as premiações de Hilda Machado, Lucia Hiratsuka, Júlia Medeiros e Fernanda Young no Prêmio Jabuti, de Ana Paula Maia, no Prêmio São Paulo, e de Djaimilia Pereira de Almeida, no Prêmio Oceanos, todas ocorridas em $2019^{4}$.

Para não extrapolar as dimensões deste artigo, duas vertentes recebem destaque: o realismo e a hibridização entre mídias. O realismo como modo de representação ultrapassa as barreiras do tempo, como demonstrou Pellegrini em Realismo e realidade na literatura. Um modo de ver o Brasil:

O realismo veio acompanhando [...] as alterações da sociedade e de regimes políticos, que passaram da aparente circunspecção e conservadorismo do Império agrícola às agitações industriais modernistas, para atravessar depois duas ditaduras "modernizantes" e ingressar, com a volta da democracia, na era do livre mercado e da imagem eletrônica. (PELLEGRINI, 2018, p. 223)

Esse percurso sempre teve como componente a violência, porém sua representação adquiriu maior concretude e novos modos de manifestação, tanto a violência real da vida cotidiana, quanto sua própria representação, em todas as mídias, afirmando-se como um dos elementos estilísticos da contemporaneidade.

A expressão da violência assume diferentes formas, sendo uma delas a brutalidade direta, sem rodeios, de certa forma herdeira do "brutalismo" inaugurado por Rubem Fonseca nos anos 70 , que permanece hoje na prosa contundente de

\footnotetext{
${ }^{3}$ Disponível em: http://filipe.tripod.com/LLobo.html. Acesso em: 14 out. 2020.

${ }^{4}$ Anteriormente, destacaram-se como finalistas do Prêmio Jabuti Sheila Smaniotto (2016), Maria Valéria Rezende (2017) e Carol Bensimon (2018); do Prêmio São Paulo de Literatura Maria Valéria Rezende (2017) e Ana Paula Maia (2018); e vencedora do Prêmio Oceanos, Marilia Garcia (2018).
} 
Marcelino Freire, Fernando Bonassi e Marçal Aquino. Mas a violência pode ser representada em formas esteticamente mais elaboradas, por esses e outros autores como Luiz Ruffato e Joca Reiners Terron que, no entender de Schöllhammer,

[...] conjugam os temas da realidade social brasileira ao compromisso com a inovação das formas de expressão e das técnicas de escrita. Abrindo, dessa maneira, caminho para um outro tipo de realismo, cuja realidade não se apoia na verossimilhança da descrição representativa, mas no efeito estético da leitura, que visa a envolver o leitor afetivamente na realidade da narrativa. (SCHÖLLHAMMER, 2011, p. 59).

A literatura mostrou-se receptiva em relação às inovações tecnológicas desde o momento em que estas últimas adentraram os campos das artes e da cultura. As movimentações entre o livro impresso e as mídias audiovisuais e eletrônicas intensificam-se continuamente, como se observa em formas ficcionais com ampla circulação na web. Essa aproximação deu origem ao que se define genericamente como hibridização, processo que ocorre em diversos níveis. No nível do texto, alterouse o modo de registrar a materialidade ou a visualidade na narrativa, em decorrência da proliferação das imagens eletrônicas e do ritmo acelerado que a informatização imprime a todos os campos da atividade humana. Recursos como fragmentarismo textual, rupturas sintáticas, mudanças frequentes de foco narrativo, elipses que estabelecem recortes em estilo de filme ou videoclipe fazem parte dessa hibridização. Recursos semelhantes estão presentes na literatura há longo tempo, porém adquirem hoje maior frequência e diversidade.

Uma das propriedades da narrativa literária é o seu potencial para transmutarse facilmente em outros tipos de texto, como, aliás, perceberam os primeiros produtores de filmes, no alvorecer do século XX e da era das imagens em movimento. No contexto da sociedade globalizada, crescem as possibilidades de criação e recriação de narrativas para atender às exigências de produção em série e de constantes inovações e substituições de produtos. Nem sempre esse aspecto traz contribuições significativas à criação literária, do ponto de vista da qualidade, porém surgem desse modo outras possibilidades para a atuação de escritores, muitos dos quais se tornam roteiristas, produtores de conteúdo ou participantes em outras atividades relacionadas ao trânsito entre linguagens e mídias. 
A hibridização repercute em outros componentes do texto literário, em especial na expressão da subjetividade. A espetacularização do eu permite ao sujeito da criação instalar-se no centro da cena e exibir - eventualmente de modo irônico - a relação entre o escritor e as demandas da escrita frente às estratégias das mídias e do mercado editorial. Sem alarmismo, é necessário reconhecer que as imposições da cultura midiática comportam um risco de conduzir à crise e à exaustão a figura do escritor na contemporaneidade.

A multiplicidade apontada por teóricos contemporâneos em nossa literatura não se limita à entrada de novos protagonistas, em uma heterogeneidade que pressupõe coexistência em espaços culturais e sociais ampliados. Desde os anos finais do século passado, anunciavam-se temáticas hoje bastante produtivas, como o multiculturalismo, a migração, a construção identitária.

O memorialismo e outras expressões da subjetividade repercutem na prosa contemporânea, configurando-se como produções em movimento contínuo, que não rejeitam a renovação nem sofrem abalos em sua densa carga semântica. São frequentes os relatos autobiográficos ou autoficcionais.

É importante registrar a persistência do regionalismo, apesar do questionamento a que esse conceito tem sido submetido, sendo mais adequado referir-se hoje a um "pós-regionalismo", com novas formas expressivas, distantes dos riscos da simplificação folclórica ou da "cor local".

A escrita renovada aplica-se a outros gêneros narrativos, como o fantástico, abordado de forma original, seja em contextos de violência, seja em atmosferas de suspense, configurando uma espécie de neofantástico.

A heterogeneidade, a multiplicidade e o hibridismo demonstram a vitalidade da produção literária contemporânea, em obras de indiscutível qualidade, publicadas pelos já "veteranos" que estão em nosso panorama literário desde os anos 80 ou 90 e pelos estreantes que surgem e se consolidam. Em contraposição a essa vitalidade, encontra-se a precariedade do mercado do livro, tanto do ponto de vista da produção, que havia obtido enorme impulso nas pequenas editoras que otimizaram o emprego de recursos digitais e comunicacionais, quanto na comercialização, pois a divulgação assegurada pelas mídias eletrônicas não basta para compensar as perdas decorrentes do fechamento de livrarias.

\section{Considerações finais}


Explicitou-se desde o início deste estudo a intenção de se delinear um breve panorama da narrativa literária brasileira dos últimos decênios como contribuição à sua historiografia. A construção historiográfica implica o contato direto com a produção literária, a análise e interpretação de componentes temáticos e opções estéticas que coexistem ou se sucedem e a adoção de prioridades que, independentemente das intenções de quem pesquisa, implicam gosto pessoal e juízo de valor.

Uma história da literatura pode ainda ser escrita, no contexto contemporâneo? Determinadas questões precedem o objetivo da sistematização historiográfica sobre os decênios recentes. Impõe-se o reconhecimento da perda da antiga estabilidade conferida à historiografia em forma de cânone, o que não implica, por outro lado, a impossibilidade da construção de pilares sobre os quais se possa erigir algum ordenamento, mediante necessárias ressalvas quanto a seu caráter provisório e não normativo.

Hoje a pluralidade temática é capaz de abarcar componentes que estiveram ausentes da historiografia tradicional, com espaços para narrativas que problematizam as etnias, os credos, as identidades sociais e de gênero, o preconceito, a discriminação. Afirmam-se alguns desses temas como novidades, ao passo que outros fazem parte da nossa literatura desde tempos remotos; o que há de novo na literatura é a possibilidade de expressão de novas vozes, diferentes pontos de vista. Iniciada em tempos recentes, opera-se com força a subversão do cânone da literatura brasileira, constituído quase inteiramente de autores masculinos e brancos. Esse fato se observa na conquista de espaços midiáticos por obras escritas por segmentos específicos ou por minorias que nunca tiveram voz, razão suficiente para que se alinhem os temas da historiografia contemporânea.

\section{Referências}

ACÍZELO, R. Historiografia da literatura brasileira. Textos fundadores (1825-1888). Vol 2. Rio de Janeiro: Caetés, 2014.

ASSIS, M. de. Notícia da atual literatura brasileira: instinto de nacionalidade. In: $O$ Novo Mundo, 24 mar. 1873. Disponível em: www.dominiopublico.gov.br. Acesso em: 10 nov. 2020.

BOSI, A. História concisa da literatura brasileira. São Paulo: Cultrix, 1985. 
BOSI, A. "Situação e formas do conto brasileiro contemporâneo". In: BOSI, A. O conto brasileiro contemporâneo. São Paulo: Cultrix, 1975.

CASTELLO, J. A. A literatura brasileira. Origens e unidade. São Paulo: Edusp, 1999. CBL. "Setor editorial brasileiro encolheu 20\% entre 2006 e 2019". Disponível em: http://cbl.org.br/imprensa/noticias/setor-editorial-brasileiro-encolheu-20-entre-2006-e2019. Acesso em: 17 nov. 2020.

DALCASTAGNĖ, R. (Org.). Fora do retrato: estudos de literatura brasileira contemporânea. Vinhedo (SP): Horizonte, 2012.

DAMASO, M. (org.) Amores em quarentena. São Paulo: Monomito, 2020.

FRANCO, R. Itinerário político do romance pós-64: A festa. São Paulo: Ed. da Unesp, 1998.

GASPARI, E. A ditadura envergonhada. São Paulo: Companhia das Letras, 2002.

GEISLER, L.; FERRONI, M.; POLESSO, N. B.; MACHADO, S. M. Corpos secos. Rio de Janeiro: Alfaguara, 2020.

GRISOTTI, M. Pandemia de Covid-19: agenda de pesquisas em contextos de incertezas e contribuições das ciências sociais. Physis. 2020, n. 30, v. 2. Disponível em: https://www.scielosp.org/article/physis/2020.v30n2/e300202/. Acesso em: 16 nov. 2020.

HUTCHEON, L. Poética do pós-modernismo - História - Teoria - Ficção. Rio de Janeiro: Imago Editora, 1991.

MIRABAI, G. Ana de corona. São Paulo: Ciao Editorial, 2020.

MOISÉS, M. História da literatura brasileira. São Paulo: Cultrix, 2019.

MONTEIRO, T. "Como o mercado de livros foi impactado pela pandemia". Disponível em: $\quad$ https://www.meioemensagem.com.br/home/marketing/2020/08/14/como-omercado-de-livros-foi-impactado-pela-pandemia.html. Acesso em: 16 nov. 2020.

NEJAR, C. História da literatura brasileira. Da Carta de Caminha aos contemporâneos. São Paulo: Leya; MinC - Fundação Biblioteca Nacional, 2011.

OCEANOS. Prêmio Oceanos 2019. Disponível em: https://associacaooceanos.pt/premio-2019/. Acesso em: 17 nov. 2020.

OTSUKA, E. T. Marcas da catástrofe. Experiência urbana e indústria cultural em Rubem Fonseca, João Gilberto Noll e Chico Buarque. São Paulo: Nankin, 2001.

PELLEGRINI, T. Despropósitos. Estudos de ficção brasileira contemporânea. São Paulo: Annablume; Fapesp, 2008.

PELLEGRINI, T. Realismo e realidade na literatura. Um modo de ver o Brasil. São 
Paulo: Alameda, 2018.

RESENDE, B. Os contemporâneos. Expressões da literatura brasileira no séc. XXI. Rio de Janeiro: Casa da Palavra; Biblioteca Nacional, 2008.

RIDENTI, M.; REIS, D. A.; RIDENTI, M.; MOTTA, R. A ditadura que mudou o Brasil. 50 anos do golpe de 1964. São Paulo: Zahar, 2014.

SANTIAGO, S. O narrador pós-moderno. In: SANTIAGO, S. Nas malhas da letra. Rio de Janeiro: Rocco, 2002.

SEREZA, H. C; MONTELEONE, J.(Org.). Histórias da pandemia. São Paulo: Alameda, 2020.

SÜSSEKIND, F. Literatura e vida literária. Polêmicas, diários \& retratos. Belo Horizonte: Ed. UFMG, 2004. 